\title{
Qualidade da alimentação: percepções de participantes do programa bolsa família
}

\author{
Quality of food: perceptions of 'Bolsa Familia' program participants
}

Kátia Yumi Uchimura ${ }^{1}$

Maria Lúcia Magalhães Bosi ${ }^{2}$

Flávia Emília Leite de Lima ${ }^{3}$

Vanessa França Dobrykopf ${ }^{1}$

\footnotetext{
${ }^{1}$ Faculdade Evangélica do Paraná. Rua Padre Anchieta 2770, Bigorrilho. 80730-000 Curitiba PR. katia.uchimura@fepar.edu.br ${ }^{2}$ Laboratório de Avaliação e Pesquisa Qualitativa em Saúde, Faculdade de Medicina, Departamento de Saúde Comunitária,

Universidade Federal do Ceará

${ }^{3}$ Universidade Federal de Sergipe
}

\begin{abstract}
Introduction: This study deals with perceptions of beneficiaries of the 'Bolsa Familia' Program, in Curitiba, southern Brazil, about their feeding habits. Objective: To understand the perceptions of participants of the 'Bolsa Família' Program on the quality of their food. Method: A qualitative study based on the critical-interpretive tradition, which used individual interviews as a technique for gathering empirical data from the informants. The study included 38 individuals, members of families included in the program. The discursive content was recorded on digital media and, thereafter, transcribed and analyzed. Results: After categorization, three main themes emerged: a description of food, quality of food, and feelings and experiences of individuals enrolled in the program. Conclusion: the acknowledgement of social vulnerability and consequent feeding habit insecurity to which such groups are subject was the main finding, as well as feelings of resignation.
\end{abstract}

Key words Government programs, Eating habits, Qualitative research, Public policies
Resumo Introdução Este estudo versa sobre percepções de beneficiários do Programa Bolsa Família no Município de Curitiba, região Sul do Brasil, acerca da sua alimentação. Objetivo: compreender as percepções de participantes do Programa Bolsa Família sobre a qualidade de sua alimentação. Método: Pesquisa qualitativa, baseada na tradição crítico-interpretativa, que utilizou entrevistas individuais como técnica para a apreensão dos dados empíricos junto aos informantes. Participaram do estudo 38 indivíduos, integrantes de famílias atendidas pelo programa. O conteúdo discursivo foi gravado em meio digital e, em momento posterior, transcrito e submetido à interpretação. Resultado: Após a categorização, três temas centrais emergiram: "descrição da alimentação; qualidade da alimentação; e sentimentos e vivências dos indivíduos atendidos pelo programa". Conclusão: destaca-se o reconhecimento da vulnerabilidade social e consequente insegurança alimentar a que tais grupos estão submetidos, bem como sentimentos de resignação.

Palavras-chave Programas governamentais, Alimentação, Pesquisa qualitativa, Políticas públicas 


\section{Introdução}

A política social de combate à pobreza tem por função enfrentar os desfechos sociais e econômicos desencadeados pelo Modelo Liberal Periférico e suas políticas econômicas : fraco crescimento econômico, pobreza, elevadas taxas de desemprego e baixos rendimentos.

Nesse contexto, desde 2003 a política econômica do governo federal vem implantando uma série de programas e iniciativas direcionadas aos segmentos mais pobres da população brasileira e àqueles até então excluídos de algumas políticas. O carro chefe da política social do governo atual (2011-2014) - e também do anterior - é o Programa Bolsa Família².

Criado em 20 de outubro de 2003, através da Medida Provisória no ${ }^{\circ} 132$ e regulamentado em 09 de janeiro de 2004, por meio da Lei n. 10.836, o Programa Bolsa Família (PBF) é um programa federal de transferência direta de renda, sendo considerado o maior programa nessa modalidade, na história brasileira. Tal iniciativa visa ao enfrentamento da fome e da miséria, bem como a promover a emancipação das famílias mais pobres do país. Sua operacionalização consiste no repasse mensal de valores em dinheiro para famílias cadastradas ${ }^{3}$.

Pesquisas demonstram que essa transferência representa cerca de $21 \%$ do orçamento familiar e que, em alguns municípios brasileiros, o valor concedido pelo PBF constitui-se a principal fonte de renda ${ }^{2}$.

Valendo-se do fato de esse programa integrar o Plano Brasil sem Miséria ${ }^{4}$, comprometido com a Política Nacional de Segurança Alimentar e Nutricional - PNAN e, por conseguinte, com o direito humano à alimentação adequada, este estudo versa sobre as percepções dos participantes do Programa Bolsa Família, no Município de Curitiba, acerca de sua alimentação, no sentido de dar visibilidade à produção subjetiva que permeia a utilização desse programa de transferência de renda no enfrentamento da insegurança alimentar.

Trata-se de um estudo qualitativo, parte integrante do Projeto de Pesquisa Diagnóstico Alimentar e Nutricional da população inscrita no Programa Bolsa Família, no município de Curitiba-PR.

\section{Programa Bolsa-família}

Eleito em 2002, o Presidente Luís Inácio Lula da Silva anunciou o Programa Fome Zero como carro-chefe da política social de seu governo. O Programa Bolsa Família surge um ano mais tarde, como tentativa de superar dificuldades materiais de sobrevivência, consolidando uma estratégia nacional de transferência condicionada de renda, e priorizando a família como unidade de intervenção $0^{5}$.

O referido Programa prevê quatro tipos de transferência financeira: a) Básico ( $\mathrm{R} \$ 70,00$, ou US\$44.59), pagos apenas a famílias extremamente pobres, com renda per capita igual ou inferior a $\mathrm{R} \$ 70,00 ;$ b) Variável (R $\$ 32,00$, ou US\$20.38), pagos pela existência na família de crianças de zero a 15 anos - limitado a três crianças por família; c) Variável Vinculada ao Adolescente (BVJ) (R\$ 38,00 , ou US\$24.20), pagos pela existência na família de jovens entre 16 e 17 anos - limitado a dois jovens por família); e d) Variável de Caráter Extraordinário (BVCE) (valor calculado caso a caso $)^{6}$. Os valores em dólares americanos foram calculados ao câmbio oficial de 8 de julho de 2011.

As famílias são selecionadas a partir das informações inseridas no Cadastro Único dos Programas Sociais do Governo Federal, regulamentado pelo Decreto $\mathrm{n}^{\circ} 6.135$, de 26 de junho de 2007 , instrumento de coleta de dados que tem como objetivo a identificação de todas as famílias em situação de pobreza existentes no País?

Em função dos critérios supracitados, os valores pagos pelo Programa Bolsa Família variam de $\mathrm{R} \$ 32,00$ a R $\$ 242,00$, ou de US\$ 20.38 a US\$ 154.14. Esses valores vigoram a partir das transferências realizadas em abril de $2011^{8}$.

No que concerne às interfaces com a saúde, os compromissos das famílias em relação a esse domínio estão estabelecidos na Portaria MS/MDS $\mathrm{n}^{\circ} 2.509$, de 18 de novembro de $2004^{9}$. Já no tocante à Educação, os compromissos foram definidos através da Portaria MEC/MDS n 3.789, de 17 de novembro de $2004^{9}$.

De acordo com o art. $2^{\circ}$ do Decreto 5.209, de 17 de setembro de 2004, o qual trata das responsabilidades e competências da União, é de responsabilidade do Ministério do Desenvolvimento Social e Combate à Fome (MDS) a coordenação, a gestão e a operacionalização do Programa Bolsa Família. Tais atividades incluem: a realização de procedimentos necessários à concessão e ao pagamento das transferências; a gestão do Cadastramento Único do Governo Federal; bem como a supervisão do cumprimento das condicionalidades e da oferta dos programas complementares ${ }^{10}$.

Dados referentes a junho de 2011 apontam 12.999.560 famílias assistidas, atingindo um montante mensal no valor de $\mathrm{R} \$ 1.470 .915 .862,00^{11}$. 
Segundo estimativas do IBGE (PNAD 2006), o número de famílias pobres (renda per capita familiar até $\mathrm{R} \$ 140,00$ ) com perfil para inclusão no PBF seria de 12.995.195 famílias $^{11}$, revelando uma cobertura de $100,03 \%$ no território nacional. Em Curitiba, cenário deste estudo, 43.708 famílias são beneficiadas pelo BF (cobertura de 86,43\%), representando um repasse mensal de $\mathrm{R} \$$ 4.333.772, $00^{11}$.

\section{Percurso metodológico}

Dada a natureza do objeto, o estudo se orientou pela abordagem qualitativa, tendo em vista o lugar essencial dessa vertente no âmbito da investigação social (e em saúde), sempre que esta se voltar para dimensões simbólicas, demandando compreensão.

O espaço de observação, neste estudo, referese ao Município de Curitiba, Capital do Paraná, que se divide em nove Distritos Sanitários, cuja demarcação territorial corresponde à divisão do espaço geográfico em administrações regionais.

A população pesquisada foi constituída por integrantes de famílias inscritas no Programa Bolsa-Família, residentes na área de adscrição do Município de Curitiba. A escolha dos informantes nesta investigação se fundamentou nos pressupostos da tradição qualitativa, na qual não se confere relevância à representatividade estatística da amostra, no sentido de possibilitar a generalização dos achados ${ }^{12-14}$. Nestes termos, a amostra foi dimensionada a ponto de permitir a saturação teórica ${ }^{15,16}$ e a subsequente compreensão, em profundidade, da produção subjetiva emergente na relação com os grupos/ atores investigados.

Com base nesses critérios de amostragem qualitativa, os informantes deste estudo correspondem a uma subamostra de participantes do inquérito quantitativo (projeto original do $\mathrm{CNPq}$ ). Os critérios adicionais de composição da amostra teórica foram: ter participado previamente do componente quantitativo do estudo e apresentar idade superior a 18 anos.

A obtenção de informação qualitativa foi realizada por meio de entrevistas individuais, em profundidade. Foram entrevistados 38 indivíduos pertencentes a famílias beneficiárias do programa, pertencentes a nove Distritos Sanitários do Município de Curitiba, tendo sido o conteúdo gravado após consentimento dos mesmos.

Observamos que a suficiência da amostra, valendo-se do critério de saturação, foi atingida a partir da décima quarta entrevista, numerica- mente extrapolada pelo fato de que a obtenção do material qualitativo acompanhou a coleta de dados do componente quantitativo da pesquisa, prevendo atingir famílias participantes residentes nas áreas de abrangência de todos os Distritos Sanitários do Município.

O instrumento utilizado foi um roteiro norteador, desdobrado em outras questões, a partir do conteúdo emergente nas narrativas. As perguntas do roteiro solicitavam o pronunciamento do informante acerca das percepções sobre sua alimentação, sobre os motivos que levavam à formação de juízos e opiniões, sobre os usos/ destino do recurso do programa e sobre sentimentos inerentes ao recebimento dessa transferência de renda.

A estratégia para entrada em campo contou com a localização das famílias inscritas por meio das unidades de saúde onde estavam cadastradas. As entrevistas foram realizadas em seus domicílios, considerando o fato de esse local constituir um ambiente mais favorável para tal finalidade. Os entrevistadores, previamente treinados para a atividade, estiveram acompanhados por ACS (Agentes Comunitários de Saúde) e se apresentaram como pesquisadores sem vínculos com o programa em foco.

Em momento posterior, as entrevistas foram transcritas e processadas e, em seguida, o material empírico foi submetido à leitura transversal, de maneira a permitir a impregnação pelo sentido do "todo" de cada depoimento, bem como a identificação das unidades temáticas indicativas dos vários temas ou dimensões presentes nas narrativas e que constituíram os eixos de significação da análise empreendida.

A proposta metodológica deste estudo fora previamente apreciada e aprovada pelo Comitê de ética em Pesquisa da Faculdade Evangélica do Paraná, submetendo-se à Resolução 196/96.

\section{Resultados e discussão}

No processo de análise, destacaram-se 3 temas centrais, a saber: descrição da alimentação; qualidade da alimentação; e sentimentos e vivências dos indivíduos atendidos pelo programa.

$\mathrm{Na}$ descrição da alimentação, primeiro tema ressaltado, chamou-nos a atenção o entendimento acerca do que constitui uma alimentação "normal" para os usuários. Para que seja assim caracterizada, leva-se em consideração o fato de a alimentação ser constituída por preparações comuns a todas as famílias (interessante observar 
como normal se assemelha a norma, no sentido de média - valor em torno do qual se distribui a maior parte dos casos), ou seja, o fato de o consumo alimentar se assemelhar ao de seus pares, pautando-se, portanto, por vivências compartilhadas em uma dada cultura, e não por um saber científico (que poderia ser representado pela composição nutricional, adequação, proporcionalidade entre grupos de alimentos, muito embora tais aspectos não tenham sido solicitados na entrevista) do que é consumido, não encerrando, necessariamente, uma qualificação positiva da alimentação, mas parte de um ethos do grupo:

É arroz, feijão, uma linguiça, uma carne, um ovo e café. [...] então eu acho que é normal como todas as outras casas... (u15)

É presente, entre os entrevistados, a caracterização de sua alimentação como tendo pouca variedade. Nesse caso, evidencia-se um reflexo do pouco acesso que estas famílias têm a uma alimentação adequada. De outra parte, constata-se certa resignação no reconhecimento de uma normalidade não desejada, mas imposta por dificuldades materiais de acesso.

A minha alimentação é o mesmo cardápio de sempre: o arroz, salada, leite, coisa de sempre de costume da gente. Não muda nada: carne, salada, pão, não muda nada... (u2)

Também se observa a permanência, entre os usuários, da incerteza de se dispor regularmente de alimento.

É, não tem tudo todo dia. Mas, quando eu posso, eu compro e dou. Não é todo dia que eles têm uma fruta, uma verdura... (u8)

Conforme sustentam Marin-León et al. ${ }^{17}$, as estratégias utilizadas para enfrentar as adversidades materiais incluem a diminuição da variedade da dieta e da quantidade de alimentos. Em nosso entendimento, tal situação se distancia muito da ideia de uma estratégia deliberadamente adotada por conveniência, já que consiste em condição imposta pela impossibilidade da compra, o que diverge, portanto, da noção de uma escolha feita pelas pessoas.

Diante do consumo bastante restrito em termos de variedade de grupos alimentares, o arroz e o feijão revelam-se como as preparações sempre presentes.

Ah, é mais é um arroz, feijão.... Uma vez por semana uma carne, alguma coisa (risos). (u34)

Feijão e arroz. [...] Quando tem condições um pedacinho de carne. (u37)

A insegurança alimentar também se expressa nas descrições dos usuários, permanecendo entre eles a incerteza da disposição do alimento e a vivência da fome. Nestes casos, o auxílio oferecido pelo PBF revela-se insuficiente para cobrir as demandas de algumas famílias, e o programa, ao que parece, não atinge a efetividade no tocante a um de seus principais objetivos, que é promover a segurança alimentar e nutricional e auxiliar no combate à fome e à pobreza.

Eu acho que a gente come muito mal [...]. Então, [...] a gente come mal mesmo [...] é arroz, feijão, carne e olha lá... (u23)

Em 2004, dados da Pesquisa Nacional por Amostra Domiciliar - PNAD revelavam 12,5 milhões de domicílios ainda vulneráveis à fome e que não recebiam repasses do governo. E, dentre os beneficiados por projetos de transferências de renda, a maioria (66\%) relatou algum nível de insegurança alimentar ${ }^{18}$.

Atualmente, os rendimentos provenientes de transferências, incluindo aposentadorias, pensões públicas e privadas, bolsas de estudos e programas sociais de transferência de renda, correspondem a segunda maior participação $(18,5 \%)$ no rendimento total da população, ficando atrás apenas dos rendimentos provenientes de trabalho $(61,1 \%)^{19}$, segundo os resultados da Pesquisa de Orçamentos Familiares - POF 2008-2009. Nesse contexto, as despesas com alimentação representam $16,1 \%$ da despesa total e $19,8 \%$ das despesas de consumo realizadas pelas famílias brasileiras.

A POF 2008-2009 também investigou a satisfação das famílias em relação à quantidade de alimentos consumidos. Comparados com a POF 2002-2003, os resultados de 2008-2009 revelam uma melhor satisfação das famílias nesse quesito, em todas as regiões do país, pois $64,5 \%$ das famílias investigadas avaliaram suficiência de quantidade de alimentos, ante $53 \%$ da pesquisa anterior. No entanto, $35,5 \%$ das famílias afirmaram insuficiência regular ou eventual na quantidade de alimento consumido.

É importante assinalar que, entre os entrevistados, a opinião sobre a qualidade da alimentação diverge: há aqueles que interpretam sua alimentação como incorreta ou inadequada e, de outra parte, aqueles que a consideram boa. A opinião negativa acerca da alimentação é ocasionada por motivos diversos, entre os quais: falta ou ausência de frutas e verduras decorrentes do custo elevado desses alimentos.

Ah... Na qualidade eu acho que não está muito boa porque eu não como muita verdura. Precisava comer mais verdura, mais fruta, e eu não sou muito assim de verdura não. Não como quase... (u3)

Ah, eu acho que é muito pesada e eu tenho que comer mais salada, mais fruta. Ainda está pe- 
sada... Pra mim tinha que ter mais fruta, mais legumes. Mas só que não tem condição de ficar comprando... A minha vontade era tomar só suco natural, só fruta, bastante... (u14)

Observamos, no relato abaixo, a ideia de que uma alimentação adequada é considerada distante das possibilidades materiais, ainda que tal "fórmula" de alimentação seja desconhecida.

Que nem às vezes eu ouço e vejo no rádio e na televisão que a alimentação tem que ser balanceada, que dizem, mas eu nem sei como (é) que tem que ser na realidade mesmo. Eu não sei o que é uma alimentação certa... Pra mim, o que eu como é certo, mas eu não sei. Também acho que nem teria condições de comer coisas certas, exatamente como é... para ter saúde. (u9)

$\mathrm{O}$ excerto acima encerra dois importantes aspectos tocantes à segurança alimentar e nutricional: no plano objetivo, o desconhecimento acerca do que se constitui uma alimentação saudável, fato que aponta uma demanda ainda pulsante para ações de educação alimentar e nutricional, ainda que essa prática tenha dado sinais de esgotamento - isso muito em função das frágeis abordagens historicamente utilizadas; e, num plano subjetivo, aparece a percepção de que uma alimentação assim qualificada não estaria materialmente ao alcance da população de menor poder aquisitivo, demonstrando a impregnação pelo estigma de inferioridade inerente à identidade social da pobreza construída nos países ocidentais $^{20}$.

Vale destacar os termos utilizados pelos entrevistados para caracterizar sua alimentação. Para alguns, a inadequação alimentar está associada à noção de "comida fraca", embora essa alimentação seja constituída de preparações mais energéticas. Para outros, a inadequação tem base no mesmo motivo, mas é qualificada como "comida bruta". Essas caracterizações podem ser entendidas como diferentes maneiras de entender $o$ ato de alimentar o corpo ${ }^{21}$.

Fraca um pouco. Porque não (é) aquela, como é que se diz? Alimentação adequada... É o feijão, o fubá, o pão que eu faço em casa... Tudo é feito em casa [...] por isso que eu digo que é muito fraca, é isso aí. Por que você sabe que tem que ter sempre uma vitamina a mais na alimentação, não é verdade? Por isso eu acho que é fraca. (u6)

Eu acho que não tem muita qualidade não. A minha alimentação, se eu fosse comer ela regularmente, assim bem normal, eu acho que eu estaria com $100 \mathrm{~kg}$. Porque é uma comida bruta: arroz, feijão, coisa forte que só engorda. Eu acho que ela não é uma comida assim... Ela é saudável porque é um alimento, alimenta a gente, agora... sei lá... (u9)

Em relação aos motivos que levam os usuários a manterem uma opinião positiva acerca da alimentação são diversos, dentre os quais se destacam: relação estabelecida entre saúde, bem-estar e alimentação; variedade na aquisição de gêneros alimentícios e preparação dos mesmos; resignação em ao menos ter o que comer.

Alguns usuários caracterizam sua alimentação como "comida forte", a qual é constituída por preparações hipercalóricas e em geral hiperlipídicas, muito longe de ser nutricionalmente adequada, mas que são vistas de maneira positiva pelo fato de que, no entendimento do grupo, "sustentam" o corpo.

Até meu filho que foi pra São Paulo, ele tinha vontade e brigava com a mulher dele: 'poxa, eu tava com uma vontade de comer a comida da minha mãe, porque a comida da minha mãe é forte, o alimento da mãe é forte', fiz lá um virado bem feito [...] bacon tudo quanto é coisa. E taquei as linguiças. (u14)

Como mencionado, a comida recebe valores simbólicos como "fraca", "pesada", "bruta", representando diferentes maneiras de entender o ato de alimentar o corpo ${ }^{20}$. Woortmann ${ }^{22}$ afirma que "só os alimentos fortes são comida. O principal indicador da 'fortidão' do alimento é dado pela sensação de saciedade que propicia".

Em contraposição ao que é considerado "normal", mas não necessariamente bom, os informantes descrevem o que, em sua análise, seria considerado "ideal".

(Uma alimentação boa) é não passar fome. (u21)

Ah, ter uma alimentação completa. E que não falte. Que tenha todo dia [...] o arroz, o feijão, a salada, carne [...] e verdura... (u33)

Tivesse um café melhor. Sei lá ... Alguma coisa melhor ... Pão com margarina, mais coisa... Carne... Não só dorso de galinha (risos) (u32).

Conforme já antecipado, sentimentos de resignação se mostram presentes nas falas dos entrevistados, demonstrando que o fato de "ter" o alimento constitui motivo suficiente para se apreciar a alimentação e afirmando a necessidade de sujeição imposta àqueles que vivenciam a precariedade de recursos materiais. Destacamos os trechos ilustrativos dessa afirmativa.

Pra mim eu acho boa [...]. Um dia você come arroz com uma carne diferente [...] Outro dia você come um arroz com feijão e ovo [...]. Porque tem muitas pessoas que não tem isso [...]. Então, mesmo que fosse um arroz e feijão, tava bom. (u12) 
Eu acho que a gente se alimenta bem. Como pobre, pra gente não falta nenhum alimento, graças a Deus! (u21)

Tá bom, tá bom. Porque o diferente... Sei lá eu acho que... A gente come... Pelo dinheiro que a gente ganha, está bom. (u26)

A gente acha boa [...] é ruim porque ninguém tem condições de comer comida boa, então a gente tem que comer o que a gente tem condição de comprar. (u37)

O sentimento de satisfação associado ao reconhecimento da transferência de renda como uma ajuda financeira é comum nas narrativas dos usuários. Permanece, entre eles, o sentimento de necessidade, de que tal ajuda é necessária.

Ah, me sinto bem, não posso falar pra você que isso não ajuda nada, mas pra mim pelo menos ajuda... (u1) [grifo nosso]

Ah, eu acho bom, eu acho ótimo o bolsa família, porque é uma ajuda dentro de casa. [...] Ah me sinto bem... (risos). (u3) [grifo nosso]

A vulnerabilidade social é reconhecida pelos sujeitos e, por essa razão, estes demonstram entendimento dos motivos da sua inclusão como destinatários dessa política compensatória. Tal situação aparece como desencadeadora de certo constrangimento, já que, em falas como os excertos abaixo transcritos, aparece a defesa do emprego e do salário justo em oposição à liberação da transferência de renda por tempo indeterminado. Em outros termos, algumas pessoas prefeririam não precisar dessa ajuda, julgando mais digno e honroso ter meios próprios para a obtenção de sua alimentação.

A eu preferia assim não precisar. Queria um emprego assim, bom, mas não consigo... Mas já que tem essa ajuda, é bem vinda ... (u4)

Olha, eu gostaria de não receber... De não precisar receber [...], não por orgulho [...]. Porque tem gente que eu falo assim e pensa que eu sou orgulhosa... Pobre, humilde, bem pobre mesmo e orgulhosa, mas não é orgulho; eu gostaria de ter um ótimo salário, ganhar bem e não precisar e deixar pra quem precisasse mais do que eu. (u9)

\section{Considerações finais}

Da análise das percepções da população inscrita no Programa Bolsa Família sobre a qualidade de sua alimentação, depreende-se o reconhecimento da insegurança alimentar e da vulnerabilidade social, bem como sentimentos que denotam certa resignação inerente a tal vivido.

Conforme assinalado, essa produção subjetiva, afastando-nos de uma leitura idealista que confere à produção simbólica o estatuto de mera representação, vincula-se nesta análise à materialidade da vida, sendo consequência da dificuldade de acesso que as famílias têm ao alimento, tanto em qualidade como em quantidade. E, nesse contexto, há que reconhecer a importância no plano material do PBF, já que, para algumas famílias, o acesso ao programa constitui sua principal fonte de renda, ainda que essa iniciativa faça parte de uma política social compensatória, ou seja, aquela que pode trazer resultados no curto prazo, com soluções que não primam pela permanência.

Embora a afirmativa a seguir necessariamente se relacione aos resultados apresentados no estudo, cabe assinalar que a redução da desigualdade social e da pobreza no Brasil só poderá ser realmente efetiva se outras ações, de natureza intersetorial, capazes de provocar um impacto mais efetivo e sustentável forem bem desenvolvidas, como por exemplo, geração de trabalho e renda, ações em saúde, habitação, educação e saneamento.

Assim, defendemos a incorporação de ações de educação alimentar, desde que adaptadas ao repertorio cultural dos distintos segmentos sociais, já que foram observados relatos de desconhecimento acerca do que constitui uma alimentação saudável. No entanto, colocamos em relevo que os determinantes da situação encontrada não necessariamente poderão ser equacionados somente com educação alimentar.

Nesse sentido, sustentamos a posição de que as ações que objetivem impactar efetivamente na insegurança alimentar da população devem contemplar a valorização social do sujeito, aliandose, invariavelmente, às necessárias mudanças estruturais na sociedade. 


\section{Colaboradores}

KY Uchimura e FEL Lima participaram da concepção e desenho do estudo. KY Uchimura, VF Dobrykopf, MLM Bosi e FEL Lima participaram da análise e interpretação do material discursivo. KY Uchimura e MLM Bosi trabalharam na redação do artigo.

\section{Referências}

1. Druck G, Filgueiras L. Política social focalizada e ajuste fiscal: as duas faces do governo Lula. Revista Katal 2007; 10(1):24-34.

2. Marques RM, Mendes A. Servindo a dois senhores: as políticas sociais no governo Lula. Revista Katal 2007; 10(1):15-23.

3. Brasil. Ministério do desenvolvimento Social e Combate à Fome. Bolsa Família (BF). [site na Internet]. [acessado 2007 mar 12]. Disponível em: http:// www.mds.gov.br/bolsafamilia/o_programa_bolsa_ familia/o-que-e..

4. Brasil. Ministério do desenvolvimento Social. Plano Brasil Sem Miséria. [site na Internet]. [acessado 2011 nov 22]. Disponível em: http://www.brasilsem miseria.gov.br/conheca-o-plano/

5. Burlandy L, Magalhães R, Monnerat GL, Schottz V. Programa Bolsa Família: nova institucionalidade no campo da política social brasileira? Revista $\mathrm{Ka}$ tal 2007; 10(1):86-94.

6. Brasil. Ministério do Desenvolvimento Social e Combate à Fome. Bolsa Família (BF). [site na Internet]. [acessado 2011 jul 7]. Disponível em: http:/ /www.mds.gov.br/bolsafamilia/beneficios.

7. Brasil. Ministério do desenvolvimento Social e Combate à Fome. Bolsa Família: Cadastro Único. [site na Internet]. [acessado 2011 jul 7]. Disponível em: http://mds.gov.br/bolsafamilia/cadastrounico.

8. Brasil. Ministério do Desenvolvimento Social e Combate à Fome. Bolsa Família (BF). [site na Internet]. [acessado 2011 jul 7]. Disponível em: http:/ /www.mds.gov.br/bolsafamilia

9. Brasil. Ministério do desenvolvimento Social e Combate à Fome. Bolsa Família (BF). [site na Internet]. [acessado 2007 set 10]. Disponível em: http:// www.mds.gov.br/bolsafamilia/condicionalidades/oque-sao-condicionalidades.

10. Brasil. Ministério do desenvolvimento Social e Combate à Fome. Bolsa Família (BF). [site na Internet]. [acessado 2011 jul 7]. Disponível em: http://www. mds.gov.br/bolsafamilia/estados_e_municipios/ responsabilidades-e-competencias.

11. Brasil. Ministério do Desenvolvimento Social e Combate à Fome. MDS em números. [site na Internet]. [acessado 2011 jul 7]. Disponível em: http:// aplicacoes.mds.gov.br/sagi/ascom/index.php?cut $=$ aHR0cDovL 2 FwbGljYWNvZXMubWRzLmdv di5ici9zYWdpL2FzY29tL2dlcmFyL2luZGV4LnBocA== $\& \mathrm{def}=\mathrm{v}$

12. Minayo MCS. O desafio do conhecimento: pesquisa qualitativa em saúde. $5^{a}$ ed. São Paulo, Rio de Janeiro: Hucitec, Abrasco; 1998.

13. Patton MQ. How to use qualitative methods in evaluation. $2^{\text {nd }}$ ed. Newbury Park: SAGE; 1987.

14. Triviños ANS. Introdução à pesquisa em ciências sociais: a pesquisa qualitativa em educação. São Paulo: Atlas; 1987.

15. Fontanella BJB, Ricas J, Turato ER. Amostragem por saturação em pesquisas qualitativas em saúde: contribuições teóricas. Cad Saude Publica 2008; 24(1):17-27. 
16. Strauss A, Corbin J. Pesquisa qualitativa: técnicas e procedimentos para o desenvolvimento da teoria fundamentada. Tradução de Luciane Oliveira da Rocha. 2a ed. Porto Alegre: Artmed; 2008.

17. Marín-León L, Segal-Corrêa AM, Panigassi G, Maranha LK, Sampaio MAS, Pérez-Escamilla R. A percepção de insegurança alimentar em famílias com idosos em Campinas, São Paulo, Brasil. Cad Saude Publica 2005; 21(5):1433-1440.

18. Instituto Brasileiro de Geografia e Estatística (IBGE). Pesquisa Nacional por Amostra de Domicílios - PNAD 2004: comentários. [site na Internet] [acessado 2011 dez 26]. Disponível em: http://www.ibge.gov.br/ home/estatistica/populacao/trabalhoerendimento/ pnad2004/comentarios2004.pdf

19. Instituto Brasileiro de Geografia e Estatística (IBGE). POF - Pesquisa de Orçamentos Familiares 2008-2009: despesas, rendimentos e condições de vida. [site na Internet] [acessado $2011 \mathrm{dez} 26]$. Disponível em: http://www.ibge.gov.br/home/estatistica/populacao/ condicaodevida/pof/2008_2009/POFcomentario.pdf

20. Uchimura KY, Bosi MLM. O mercado dos pobres: um enfoque qualitativo da utilização de programas sociais de alimentação. Cad Saude Publica 2004; 20(2):482-491.

21. Assis AMO, Freitas MCS, Oliveira TC, Prado MS, Sampaio LR, Machado AD, Queiroz DA. Bró, caxixe e ouricuri: estratégias de sobrevivência no semiárido baiano. Rev Nutr 1999; 12(2):159-166.

22. Woortmann K. Hábitos e ideologias alimentares em grupos sociais de baixa renda: relatório final. Brasília: Série Antropologia; 1978.

Apresentado em 24/11/2011

Aprovado em 26/12/2011

Versão final apresentada em 10/01/2012 